\title{
Drivers and Solutions for Food Waste in the Restoration Sector: A
} Case Study

\author{
Xira Ruiz-Campillo ${ }^{1} \&$ Elena Bulmer ${ }^{2}$ \\ ${ }^{1}$ Department of International Relations and Global History, Complutense University of Madrid, Spain \\ ${ }^{2}$ Department of Operations and Data Science, EAE Business School, Madrid, Spain \\ Correspondence: Xira Ruiz Campillo, Department of International Relations, Complutense University of Madrid, \\ Spain. E-mail: xiraruiz@ucm.es
}

Received: June 19, $2020 \quad$ Accepted: July 21, $2020 \quad$ Online Published: July 29, 2020

doi:10.5539/jfr.v9n5p32 URL: https://doi.org/10.5539/jfr.v9n5p32

\begin{abstract}
The aim of this research is to examine the main drivers of food waste in restaurants, the main tools used by the sector to reduce waste and to forward a number of solutions to waste generation. The paper uses a case study in a municipality of Madrid, Spain, where a number of restaurants' managers were interviewed. The work collects information on how restaurants manage waste, investigate what are the perceptions and attitudes of managers, and determine what kind of solutions could be put in place to reduce in the restauration sector. Findings show that although restaurant managers are aware of the footprint that food waste create, excuses for inaction - going from putting the blame on clients or the space of their premises- were commonly used in the restaurants analysed for this research.
\end{abstract}

Keywords: food waste, sustainability, restoration sector, behaviour, climate change, reduction of food waste, restaurants, sustainable practices

\section{Introduction}

Finding ways to reduce food waste has become in the last years an increasingly important topic for researchers and the international community. Food waste occurs throughout the entire food supply chain, from agricultural production, to postproduction procedures, processing, distribution, and consumption (FAO, 2011; Lipinski et al. 2013; Papargyropoulou et al., 2014). Food waste and food loss have been studied from the perspectives of agricultural production (Delgado et al., 2017; Rao \& Rathod, 2018; Chang \& Li, 2019); of consumers and households' perspective (Schanes, 2018; Boschini et al. 2020; Mattila et al., 2019; Cerciello et al., 2018; Schmidt et Matties, 2016); and of innovation, in the way food waste may be transformed into energy (Yeo et al. 2019).

While food waste levels at the end of the food chain (processing, distribution and consumption) are greater in high-income regions (FAO, 2013; Papargyropoulou et al., 2014), the waste of food incurs in economic implications for everyone participating in the food supply chain, from the farmer to the food producer and the consumer in both developed and developing countries (Papargyropoulou et al., 2014; Baldwin, 2015). Although there are several published articles on food waste in the food service industry (Betz et al., 2015; Baldwin, 2015), the extraordinary amount of food waste produced every year leaves room for additional empirical research whose objective is to contribute towards promoting and increasing sustainability in the food chain sector, and consequently, to increasing global sustainability. According to the Food and Agriculture Organization (FAO), approximately one-third of all food produced in the world is lost or wasted (FAO, 2011), with an associated cost of USD 936 billion per year, the equivalent to the GDP of Indonesia or the Netherlands (FAO, 2015). One of the advantages of food waste is that it is relatively easy to reduce, since each of us can opt to consume more responsibly, thereby contributing to the reduction of greenhouse gases. With regards to food waste, it is necessary to also mention other types of waste (non-food waste) that are generated along with the food elements, such as cardboard, plastics or glass.

In Spain, the Ministry of Agriculture, Fisheries and Food (MAPA by its current acronym in Spanish) published in 2016 a guide where it placed Spain in the thirteenth position in the amount of wasted food per inhabitant, with $176 \mathrm{~kg}$ of wasted food per year per inhabitant, most of which was generated in the stages of distribution and consumption. The MAPA identified the European Union's catering sector as responsible for $14 \%$ of the overall 
amount of food wasted in Europe (MAGRAMA, 2017). Furthermore, considering these figures, FAO estimated that there were 2 billion people suffering from food insecurity in 2019 (FAO, 2019). In October 2015, Boadilla del Monte, a municipality of Madrid, joined the Covenant of Mayors for Climate and Energy, thus committing the municipality to reduce its greenhouse gases (GHG) emissions. This paper shows part of the results of an analysis of waste management in the restoration sector promoted by Boadilla's city council with the aim of contributing to improving their waste management strategy and thus their GHG emissions.

In the European Union (EU) alone, in 2012, 88 million tons of food (the equivalent of $173 \mathrm{~kg}$ per person) were generated with an associated cost of 143,000 million euros (Stenmark et al., 2016). The European Union, through the circular economy concept, seeks to promote a new type of economic development, in which waste reduction plays a fundamental role. There are multiple causes of food waste, which exists at all levels (manufacturing, catering, domestic...), and among them are the size of the cooked portions in restaurants, the labelling legislation, the lack of planning in restaurants, food handling, procurement management or the own quality requirements of the restaurants, among others (Plascarb, 2013). The reduction of waste and the improvement of the management of the latter are of paramount importance in the reduction of greenhouse gases, and comply with Sustainable Development Goal (SDG) 12, which commits the international community to guarantee sustainable consumption and production at all levels between 2015 and 2030 (United Nations, 2015).

The reduction of food and non-food waste is aligned with Sustainable Development Goal 12, aiming to ensure sustainable consumption and production habits which will contribute towards the promotion of efficient energy and resource use and in the improvement of everyone's quality of life. Moreover, it will also promote good practices among companies and consumers with respects to the reduction in the use of resources. Specifically, Sustainable Goal 12.3 focuses on halving the global food waste per capita at the consumer level (United Nations, 2015). In short, it can be said that waste reduction has a threefold objective: (1) to reduce the environmental impact, (2) to contribute to an economy with a reduced use of resources and (3) to promote more sustainable consumption patterns.

However, very often, greenhouse gas emissions or unsustainable consumption patterns are almost exclusively linked to energy consumption, transport, or the manufacturing industry. As an example, during our data collection more than $26 \%$ of the respondents did not know the impact of food waste on climate change or on sustainability, which should probably serve as a base for more targeted information campaigns in the restoration sector. Emissions from fuel combustion (including those of transport) accounted for $79 \%$ of the total greenhouse gas emissions in Europe in 2017, followed by agriculture (10\%), industrial processes (8\%) and waste management (3\%) (Eurostat, 2019a). The amount of waste per capita has been reduced since 2009 going from 510 to $492 \mathrm{~kg}$ per capita (Eurostat, 2019b), showing that much more should be done to reduce the amount of waste generated at the European level.

This study provides an overview of how restaurants in Boadilla del Monte (Madrid) manage waste, deep on the perceptions and attitudes of managers, examines the reasons they state for those attitudes and determine what kind of solutions could be put in place to reduce waste (food and non-food) based on the findings of this study. The research questions for this study are: What are the main drivers of food waste in restaurants? What are the main tools used by the sector to reduce waste? What are the main obstacles to reducing waste? How can waste be reduced?

The argument of the paper is that although restaurant managers are aware of the footprint that food waste create, excuses for inaction are commonly used in the restoration sector. The goal of this research is thus to endeavour a diagnosis on the motivations and drivers of food waste as well as a series of recommendations on waste management in the restoration sector, thus contributing to increase the sustainability of this type of industry.

\section{Method}

The data used in this report has been collected through online surveys and semi-structured one-to-one interviews that were carried out in restaurants of Boadilla del Monte between May and August 2018. Both the surveys and the interviews enabled the collection of a large amount of data, which helped us determine what are the different realities of waste management in the restaurants of the municipality. The interview consisted in 29 questions, which covered perceptions and behaviours about waste management, food waste management, non-food waste management and general awareness on the impact of waste on sustainability. A total of 23 restaurants, fast food, non-fast food, participated in the survey.

The analysis has been completed with an extensive literature search consisting of specialised reports and papers on food waste as well as information from European and Spanish official sources to compare and contrast our local findings with those more general. To have a better perspective on the problems with waste management in 
the municipality, the authors interviewed representatives of the company in charge of the waste collection, as well as the town council environmental representative, who is currently the municipality mayor.

The paper is organized in three sections. The first one provides an overview on the perceptions of the interviewees on the contribution of food waste to climate change and unsustainability and on the main drivers of food waste in the daily running of restaurants. The second section focusses on the tools restaurants have in place to reduce waste generation within their premises and the main obstacles they identify to reduce waste, and the third section proposes a number of solutions to diminish the amount of waste generation. The paper ends with some conclusions on the analysis carried out.

\section{Results}

Most of the restaurants surveyed (87\%) perceived food waste as a real problem that should be treated at different societal levels (i.e. from individuals, to regional and national governments), and $73.9 \%$ of respondents believed that food waste contributes to climate change. These results are in line with the information published by the FAO (FAO, 2017) stating that food losses and waste represent a considerable waste of land, water, energy and agricultural inputs, and cause the emission of millions of tonnes of greenhouse gases. Almost all the interviewees (95.7\%) agreed that food waste generated economic losses; however, some restaurants pointed out that they considered those economic losses associated to food waste as something "normal", which was more dependent on customer behaviour and attitude than on a bad practice from the part of the restaurants.

According to the FAO (2013), 1,300 million meals annually end up in the trash. In developed countries, most of the food is lost in the last phase of the supply chain, at consumption, as the results of the survey point to. While consumers over-buy or overreact to expiration dates and to product preferential consumption, retailers reject large quantities of food due to the present quality and aesthetic standards. The result of all this is that up to $46 \%$ of food ends up wasted at the processing, distribution, and final consumption stages (FAO, 2013). The restaurant managers were asked on the stage in which waste was produced to have a better understanding of the extend of the problem and to elaborate adequate proposals to diminish the waste.

Many of the restaurants claimed that they had an effective food management system, and that they thereby only bought the food needed. Furthermore, 9\% of the restaurants interviewed responded that most of the food wasted derived from the unused stored food and $4 \%$ said that most food waste came from the preparation of the dishes. Interestingly, most of them blamed the clients for the food waste. On the one hand, all the restaurants surveyed said they had the habit of advising customers about the quantities of food they ordered, which is an important step towards minimizing food waste levels. But on the other, $70 \%$ of the restaurants interviewed considered that it was the clients that generated most of the food waste, which leads us to question whether adequately-sized portions of food are actually served in the restaurants that participated in the surveys, and whether "diners" are properly advised. In line with this, a total of $87 \%$ of the restaurants surveyed considered that they served proportionally correct sized food portions, which contracts with the previous affirmation and with previous research that point that serving excessive food portions increases the likelihood of eating more than we need (Benton, 2015; Brunstrom, 2011) and at the same time generates greater food waste.

Some restaurants said that they hardly generated any waste and considered themselves efficient with respect to the use of food in the preparation of their dishes. Furthermore, they said that the food at their restaurant was prepared at the time of the order, thereby minimizing the amount of food stored as well as the potential to generate waste. Considering that almost $70 \%$ of those interviewed said that most of the food waste came from the diner leftovers, as it has just been pointed out, it is interesting to examine a bit further the types of food waste that the restaurant clientele leaves. According to the interviewees, these include side dishes such as fries and salads, bread and rice and legumes, what gives us information on what kind of food may be reduced to avoid waste. This information, however, does not go in line with that published by the Spanish Ministry of Agriculture, Fisheries and Food (MAGRAMA, 2017), where only 30\% of the food waste came from the leftovers of the clients. Once again, it seems that restaurant managers tend to account the consumers for most of the food waste and not on the amount of side dishes served.

We found important to consider the type of clientele that restaurants have and the expectations of the latter with regards to quality and variety of the food. What the authors observed in their interviews was that while some restaurants claimed that their clientele would "eat until they burst", other restaurants' clients seemed to appreciate high quality dishes, and that had an influence on the attitudes of managers towards food waste management, since the former tended to understand food waste not as the consequence of an excess of food on the plate but as the gluttony of clients. Therefore, the perception of the restaurant managers on their customers' expectations and needs seem to determine how much food will be served and, subsequently, how meals and food 
orders will be planned for the short term (i.e. days or weeks).

As pointed out above, one of the aims of SDG 12 is to promote more sustainable consumption patterns. In line with this, $82.6 \%$ of the surveys and interview respondents said that they would like to be recognized for their sustainable policies and practices, which is an important point as it could potentially bring value to these restaurants by differentiating them from competitors. However, as many of them pointed to, sustainability in the restoration sector remains a vague concept that can range from using ecological cleaning products in restaurants to promoting the use of the Tupperware among the restaurants' clientele. Indeed, even those restaurants that want to be recognized as more sustainable find problems in the process. For example, some respondents recognized that they experienced difficulties in knowing where the food supplies come from. Some of the restaurants said they really did not know the origin of the food served at their restaurant. They obviously knew the suppliers but had no real knowledge of the origin of their products. This contrasts considerably with other countries, such as in some Scandinavian countries where restaurant owners even know the name of the farm from which each of the products, they serve their customers.

At present, there is no national brand or standard that recognizes sustainable catering establishments in Spain, and future research could deep in the role of national governments in the promotion of sustainable practices through the creation of standards or the promotion of tools such as blockchain, a technology increasingly used to enhance transparency in agricultural and livestock supply chains (Beef Central, 2018).

\subsection{Perceptions on Waste Management}

A set of the questions of the survey was aimed to assess how restaurants manage their non-food waste, mainly paper, plastic, and glass. The first thing that the restaurants were asked was to self-assess themselves as regards to their recycling habits and give themselves a grade out of 10 . The average score for this self-assessment was almost 8 , which shows that restaurants participating in this study considered themselves quite efficient with respect to their recycling behaviour. The pie chart below displays the type of waste restaurants said they generated the most, the most popular answer being glass and organic waste, followed by paper and plastic.

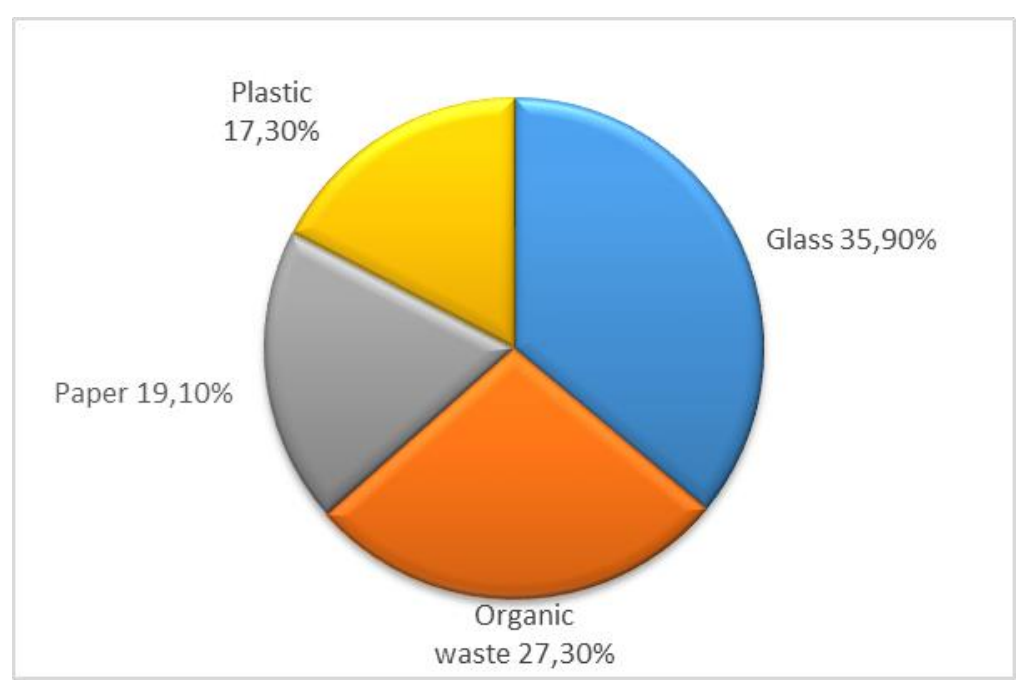

Figure 1. Percentage of answers to the question: How would you distribute the total amount of waste produced in your restaurant (total waste $=100 \%$ )

As seen in the pie chart, glass (i.e. wine, water end beer bottles) is the largest type of waste generated by restaurants surveyed $(35.9 \%)$, followed by organic waste $(27.3 \%)$. Based on these results, we understand that bigger efforts should be made to reduce both the amount of glass used (maybe considering the option of giving preference to tap water served in jugs over bottled water) and the amount of organic waste produced. In this regard, restaurants were asked on their management and on the different tools they had in place to reduce these amounts of waste.

As a way of reducing the amount of glass and plastic generated in restaurants by the bottles of water, interviewees were asked whether or not restaurants would serve tap water in jugs, to what $56.5 \%$ of respondents said that they served jugs of water to their customers if they asked for them, while $34.8 \%$ responded that they did not offer the option of serving water in jugs even though they knew that it would contribute to reduce waste. 
Although serving a glass of tap water seems easy, simple and, theoretically does not suppose an additional cost to the restaurant, the biggest claim of some restaurants was the economic part, arguing that serving tap water via a glass or a jug meant a cost for them, even if it was very small. One of the arguments given was that all restaurants pay for the water they consume like any of us in our homes, so why give it to customers for free when it costs restaurants? All restaurants serve bottled water, either in glass or plastic bottles, and their profit margin is considerable, so serving tap water in their restaurants would mean economic losses that they would not be willing to assume. The restaurants also referred to the problem of space that involves having jugs of water available to customers as a reason to deny the option of serving water in jugs. Normally, the space that restaurants have in the kitchen and bar is quite limited, so storing jugs implies the use of a space that some establishments do not have, and the limited space that they do have is used for other more priority purposes. However, managers interviewed did not seem to find any space problem in storing hundreds of bottles in their establishments.

A second set of questions were directed to the management of the organic waste produced in the restaurants. Something that the authors specifically wanted to know was whether restaurants did something with their leftovers (i.e. we need to highlight that we are referring to here to the food that does not leave the kitchen) and how they organised the separation of waste within their premises. As regards the first question, $69.6 \%$ of respondents said they did try to take advantage of their food leftovers through some of these initiatives: allowing workers to take home their leftovers; using leftovers for employees' breakfast, lunch or dinner; taking restaurant leftovers to a nursing home; preparing small snacks and "tapas" for customers when ordering a beer or a glass of wine; preparing new recipes with leftover food, such as salmorejo with the bread from the previous day.

Some interviewees told us that although these initiatives were great, there were a few elements that needed to be taken into account such as the compliance with specific food quality and safety standards and regulations, which are very important when giving leftovers to others, such as in the preparation of new snacks or recipes. This is in line with some authors that indicate that in developed nations the compliance with high health and hygiene standards are one of the main causes of food waste (Waarst, 2011), thereby the potential of rendering more flexible the current standards should perhaps be considered in order to reduce the amount of food that ends up in the trash.

Another fundamental aspect to understand waste management is related to how residue separation is carried out in the participating establishments: Although some of the interviewees admitted that during moments of elevated stress levels while serving meals, staff might not recycle properly since in those circumstances they prioritized the quick service to the clients before recycling, however, overall, $85.7 \%$ of the respondents said that they separated all of their residues in different containers. This result is very much aligned with the self-assessment mark that the restaurants gave themselves with respect to their recycling behaviour (i.e. average score of 7.98). In this regard, the company in charge of collecting organic waste and packaging in the municipality, confirmed that most restaurants did a good job in depositing their garbage in the different recycling containers; however, they pointed out some important aspects that could be improved: for example, how some restaurants sometimes left containers and paper / cardboard out of the recycling containers, and they blamed this firstly on how quickly the workers needed to throw away the waste, and secondly on the possible lack of training of some of the restaurant staff on the importance of recycling properly.

In this regard, during the surveys, data was also compiled regarding the policy and training of the restaurant staff in waste management. Although $70 \%$ of the restaurants affirmed that their staff received training in waste separation, by this most interviewees referred to the food handling course that all catering staff need to carry out to work in the restoration sector in Spain. This type of course usually lasts 10 hours, many of them are taught online and includes among the subjects to be covered a wide variety of topics, from food preservation and handling to the hygiene of the premises and staff. Therefore, amongst the knowledge acquired, there is very little that concerns the existing legislation on food waste handling and recycling or on the actual impact that recycling has on the proper functioning of the restaurants or even on its profits and losses.

We also found out that restaurants considered an especially important and determining element for recycling properly the size of their premises to store waste. Several restaurants mentioned that it would be ideal to have all four types of recycling bins in their kitchen, however the space they had did not allow it. Some of the restaurants answered that they had two of the four containers because of this reason. Other restaurants said that, logistically, they had the public recycling containers remarkably close to the street, so it was not necessary to have bins in the kitchen for the four waste types. For example, cardboard waste often takes up a lot of space, and they therefore did not store but just took it down to the nearest paper recycling container. On many occasions, restaurants receive food and other items in large cardboard boxes that take up a lot of space, even folded, therefore taking 
them outside is just easier.

Another element to consider when evaluating waste management is knowing how the latter is carried out inside the restaurant. Of the restaurants surveyed, $17 \%$ had one or more people in charge of waste separation. In some of the restaurants interviewed, it was the waiters that oversaw the separation of the waste and the throwing out the garbage, while in others the tasks were separated amongst the kitchen staff and the waiters. In $70 \%$ of the restaurants surveyed the separation of waste was everyone's tasks, and this according to some restaurant managers contributed to being efficient in the restaurant's recycling activities, while for some other respondents, it leads to inefficient recycling endeavours.

In any case, from the interviews it is impossible to deduce whether there was a person in charge of the supervision or whether the waste separation was done correctly by the restaurant workers, thereby relegating the task to the goodwill of the workers. It must be remembered here that the final responsibility is of the restaurant managers and not of the workers, therefore properly training the workers in waste management and having one or two people responsible for managing waste properly is very important. Numerous publications, for example, point out the advantages of training staff as regards to the benefits of recycling in achieving more efficient waste management in restaurants, which leads, among others, to the saving of raw materials, thereby reducing costs and improving the service that restaurants give to the clients (Norden, 2012). Some reports estimate that every tonne of food waste produced costs of $€ 2000$ (Creedon, 2010). Similarly, a more recent report by WRAP (2018) pointed out that establishments that trained staff in waste management can recover $64 \%$ of the investment after the first years and that percentage increased to $80 \%$ in two years.

Restaurants were finally asked on the initiatives they had in place to promote sustainably within the daily run of their restaurants. Although it cannot be said that the restaurants surveyed have an internal sustainability policy, $18 \%$ said they used recycled paper napkins in their establishments, although some admitted that they bought the recycled napkins because they were cheaper and not because they were more environmentally friendly. However, $37 \%$ of restaurants did say that they bought local and seasonal products as a way of contributing towards sustainability, while $18 \%$ of the restaurants interviewed informed that they chose to use cloth tablecloths as these generated less waste.

\section{Discussion}

The role of the food service sector in the reduction of food waste in developed countries is important to shift to more sustainable consumption patterns and practices and to increase awareness on the impact that food waste has on the environment or the economy (Papargyropoulou et al., 2014). While there is no single practice of reducing food waste (Mattila, 2019), below there are a set of recommendations to reduce food waste that authors propose based on the results of the analysis and after the reviewing of specialised literature, the interviews with the restaurants participating in this study, with Boadilla's environmental representative and the representatives of the company in charge of collecting organic waste and packaging in the Municipality.

\subsection{Recommendations on Training}

Sustainable restaurants not only try to offer fresh, local and seasonal products, they also efficiently control waste and manage the use of water and energy. Thus, among the most important issues in waste prevention is the training and motivation of staff (Creedon et al., 2010; Filimonau et al., 2020). This is very necessary to ensure the correct disposal of the waste. As pointed out above, although waste separation training is included in the food handling courses that people have to take to work in the restoration sector, it would be advisable to train employees with regards to the benefit of sustainability and waste recycling both for the environment and for the restaurants themselves. Another recommendation is to appoint at least one person in charge of the restaurant's waste management (ReFED, 2018). In practically all of the restaurants that were surveyed, there was normally no-one in charge of ensuring that waste disposal is carried out correctly within the restaurant and that the waste is properly separated in the premises, and deposited in the outside municipal recycling containers.

According to a Unilever report (Unilever, 2016), a 50\% reduction in food waste is potentially achievable for most restaurants. Regularly conducting a waste audit would be another way of determining restaurant waste levels, thereby potentially leading to new behaviour as regards to the purchasing, storage, preparation and the serving of rations.

Some researchers also point to the behavioural drivers behind food waste (Setti et al., 2018; Mondéjar-Jiménez et al., 2016), among of which is the lack of consumer awareness with respect to the impact of their food in the economy or the environment (Neff et al., 2015; Stancu et al., 2016; Kibler et al., 2018). The restoration sector can help improve the information customers receive in different ways. For instance, restaurants may improve 
their communication regarding and promoting the flexibility of their menu options, by giving different serving size options. Clear communication in this respect will help clients make better choices regarding how much they want to eat. Part of the communication restaurants can offer may well include the setting up of posters and placards to remind clients of the benefits of sustainable practices and of the importance of saving water or energy in restaurants.

\subsection{Recommendation on the Size of the Servings}

There are studies that point to the lack of creativity as regard to the use leftovers as a potential cause of food waste (Cappellini and Parsons, 2012; Schimidt \& Matthies, 2016; Kibler et al., 2018; Närvänen et al., 2018). Some of the restaurants surveyed made use of most leftovers by offering them as appetizers or transforming them into new dishes. Getting creative and turning leftover vegetables into tasty soups, using leftover breakfast toast for fish cakes or leftover chicken or pork to make paté are all options for reducing food waste.

Around $70 \%$ of the restaurants that participated in this study claimed that they had a policy where waiters advised customers to take their leftover food in a doggy bag. However, in many cases, restaurants did not anticipate themselves to the clients' requests but instead just offered them a doggy back when the clients said that they wanted to take their leftovers home. Perhaps this is one of the areas that may be improved to easily avoid and reduce to a minimum the cost of food waste. Catering chains, such as Starbucks, already contribute to waste reduction by giving a small discount to customers who bring their own cup for coffee (Starbucks, 2018), which could be another option to consider especially for take away restaurants. These are small gestures that may be endeavoured depending on the restaurant type (it seems a good idea for fast-food restaurants).

As Porpino (2016) points out when analysing household food waste behaviour, consumers tend to enjoy serving big portion sizes, but retailers are increasingly aware of their responsibility in reducing food waste caused by big portions. Therefore, another recommendation for restaurants is to adapt the size of their menus and servings. Adapting the size of the servings according to what the customers of each restaurant tends to consume will help to both save money and reduce food waste. The options to determine adequate portion sizes range from serving the food in front of the diners, which gives them the say regarding how much they want to eat, to offering different size offerings of the same dish. Other recommendation would include the possibility of having less extensive menus with a selection of fewer dishes, which will help restaurants be much more accurate when buying and managing food products.

The donation of food to local authorities can also be a measure to reduce food waste or to use as food for animals (Betz et al., 2015; Baldwin, 2015). Some restaurants surveyed told us that they gave part of their leftovers to charities, such as nursing homes, food banks or NGOs. Other restaurants said that the current health regulations in Spain made these initiatives difficult. Perhaps it may be possible from the part of the public administrations in Spain to encourage or facilitate the transfer of restaurant leftovers to those that need it most. In line with this there are initiatives that put restaurants or supermarkets in contact with costumers so the former can sell unconsumed food at a lower price at the end of a working day, like "11th Hour" from Singapore, "No Food Wasted" (Netherlands), "FoodCloud" (Ireland and United Kingdom) or "Too Good to Go" (Europe and the United States).

Another measure is to use the leftover organic remains of fruits and vegetables from prepared meals, etc., as compost for soil amendment, anaerobic digestion for energy or producing meals or tallow (Baldwin, 2015). Some city councils have already progressed in this respect and are presently part of the Composting Network (Composta en Red), a Spanish national network of local entities whose aim is to promote the development of public policies that are in favour of composting.

The philosophy of take-away restaurants goes hand in hand with a huge generation of waste. In these cases, establishments can also use environmentally friendly measures such as opting for recycled materials, paper / cardboard (versus plastic) (Rosa, 2018), avoiding the use of straws, compensating customers who bring their own containers or facilitating the separation of waste through the implementation of recycling containers in the restaurant premises. Alternative measures can be the use of dispensers to serve sauces such as ketchup, mayonnaise, oil, etc., instead of using individual packets.

Finally, as described in this report, some restaurant owners had a negative perspective as regards to offering free jugs of water to their clients, since there are several associated costs involved (i.e. the water, the ice, the cleaning, etc.). However, the authors of this paper consider this a good alternative to the big ecological footprint that bottled water has on the environment. An intermediate solution may be for restaurants to serve jugs of filtered water. This water could be sold like bottled water, but at a lower price (Diario de Navarra, 2018), which will help reduce the number of plastic and glass bottles used, thereby reducing the amount of waste generated. 
Furthermore, by having a filtered water system, restaurants will also be able to save on space that is currently occupied by glass and/or plastic bottles.

\section{Acknowledgments}

This work has been done thanks to the funding received from URBASER, the company in charge of in charge of collecting organic waste and packaging in the municipality, and with the support of the environmental representative of Boadilla's City Council.

\section{References}

Baldwin, C. (2015). The 10 Principles of Food Industry Sustainability. John Wiley \& Sons, Incorporated. UK. https://doi.org/10.1002/9781118447697

Beef Central. (2008). How Blockchain can Beef Up Cattle Supply Chains. Retrieved from https://www.beefcentral.com/features/ntca-conferences/how-blockchain-can-beef-up-cattle-supply-chains/

Benton, D. (2015.) Portion Size: What We Know and What We Need to Know. Critical Reviews in Food Science and Nutrition, 55(7), 988-1044. https://doi.org/10.1080/10408398.2012.679980

Betz, A., Buchli, J., Göbel, C., \& Müller, C. (2015). Food waste in the Swiss food service industry - Magnitude and potential for reduction. Waste Management, 35, 218-226. https://doi.org/10.1016/j.wasman.2014.09.015

Boschini, M., Falasconi, L., Cicatiello, C., \& Franco, S. (2020). Why the waste? A large-scale study on the causes of food waste at school canteens. Journal of Cleaner Production, 246. https://doi.org/10.1016/j.jclepro.2019.118994

Brunstrom, J. M. (2011). The control of meal size in human subjects: A role for expected satiety, expected satiation and premeal planning. Proceedings of the Nutrition Society, 70, 155-161. https://doi.org/10.1017/S002966511000491X

Cappellini, B., \& Parsons, E. (2012). The thrifty meal: re-creating value in the kitchen. Advances in Consumer Research, 40(29), 739-740. https://doi.org/10.1086/684528

Cerciello, M., Agovino, M., \& Garofalo, A. (2018). Estimating food waste under the FUSIONS definitions: What are the driving factors of food waste in the Italian provinces?. Environment, Development and Sustainability, 21, 1139-1152. https://doi.org/10.1007/s10668-017-0080-0

Chang, C., \& Li, R. (2019). Agricultural Waste. Annual Literature Review. Water Environment Federation. https://doi.org/10.1002/wer.1211

Creedon, M., Cunningham, D., \& Hogan, J. (2010). Less Food Waste. More Profit. A Guide to Minimising Food Waste in the Catering Sector. Clean Technology Centre, Cork Institute of Technology.

Delgado, L., Schuster, M., \& Torero, M. (2017). Reality of Food Losses: A New Measurement Methodology. International Food Policy Research Institute, Institute of Development Policy and Management, University of Antwerp, The World Bank. Retrieved from https://mpra.ub.uni-muenchen.de/80378/3/MPRA_paper_80378.pdf

Diario de Navarra. (2018). Agua del grifo en los bares de Pamplona: de la cortesía a la obligación. Retrieved from https://www.diariodenavarra.es/noticias/navarra/pamplona-comarca/pamplona/2017/12/31/agua-del-grifo-b ares-pamplona-cortesia-obligacion-selecciondn-569400-1702.html

Eurostat. (2019a). Greenhouse gas emission statistics - emission inventories. Statistics Explained. Retrieved from https://ec.europa.eu/eurostat/statistics-explained/pdfscache/1180.pdf

Eurostat. (2019b). Municipal waste by waste management operations. Series 2007-2018. Retrieved from http://appsso.eurostat.ec.europa.eu/nui/show.do?dataset=env_wasmun

FAO. (2011). Global Food Losses and Food Waste. Extent, Causes and Prevention. Rome, Food and Agriculture Organization.

FAO. (2013). Food wastage footprint. Impacts on natural resources. Summary report. Rome, Food and Agriculture Organization.

FAO. (2015). Food wastage footprint \& climate change. Rome, Food and Agriculture Organization.

FAO. (2017). The future of food and agriculture. Trends and challenges. Rome, Food and Agriculture Organization. 
FAO. (2019). The State of Food Security and Nutrition in the World. Safeguarding against economic slowdowns and downturns, Rome, Food and Agriculture Organization.

Filimonau, V., Zhang, H., \& Wang, L. (2020). Food waste management in Shanghai full-service restaurants: A senior manager's perspective. Journal of Cleaner Production, 258. https://doi.org/10.1016/j.jclepro.2020.120975

Kibler, K., Reinhart, D., Hawkins, Ch, Motlagh, A. M., \& Wright, J. (2018). Food waste and the food-energy-water nexus: A review of food waste management alternatives. Waste Management, 74, 52-62. https://doi.org/10.1016/j.wasman.2018.01.014

Lipinski, B., Hanson, C., Lomax, J., Kitinoja, L., Waite, R., \& Searchinger, T. (2013). Reducing Food Loss and Waste. Working Paper Installment 2 of Creating a Sustainable Food Future. Washington, D. C. World Resources Institute.

MAGRAMA. (2017). Guía práctica para reducir el desperdicio alimentario en la restauración, Madrid.

Mattila, M., Mesiranta, N., Närväen, E., Koskinen, O., \& Sutinen, U. M. (2019). Dances with potential food waste: Organising temporality in food waste reduction practices. Time \& Society, 28(4), 1619-1644. https://doi.org/10.1177/0961463X18784123

Mondéjar-Jiménez, J., Ferrari, G., Secondi, L., \& Principato, L. (2016). From the table to waste: An exploratory study on behaviour towards food waste of Spanish and Italian youths, Journal of Cleaner Production, 138, 8-18. https://doi.org/10.1016/j.jclepro.2016.06.018

Närvänen, El; Mesiranta, N., Sutinen, U., \& Mattila, M. (2018). Creativity, aesthetics and ethics of food waste in social media campaigns. Journal of Cleaner Production, 195, 102-110. https://doi.org/10.1016/j.jclepro.2018.05.202

Neff, R., Spiker, M., \& Truant, P. (2015). Wasted food: US consumers reported awareness, attitudes and behaviours. Plos One 10. https://doi.org/10.1371/journal.pone.0127881

Norden. (2012). Prevention of food waste in restaurants, hotels, canteens and catering. Nordpub.

Papargyropoulou, E., Lozano, R., Steinberger, J., Wright, N., \& Bin, U. Z. (2014). The food waste hierarchy as a framework for the management of food surplus and food waste. Journal of Cleaner Production, 76, 106-115. https://doi.org/10.1016/j.jclepro.2014.04.020

Plascarb. (2013). Report about Food Waste Statistics in Europe. Plascarb. Retrieved from https://plascarb.eu/assets/content/20151208_FoodWasteReport_WP9_final_publish.pdf

Porpino, G. (2016). Household food waste behaviour: avenues for future research. Journal of the Association for Consumer Research, 1(1), 41-51. https://doi.org/10.1086/684528

Rao, P., \& Rathod, V. (2018). Valorization of Food and Agricultural Waste: A Step towards Greener Future. The Chemical Record. https://doi.org/10.1002/tcr.201800094

ReFED. (2018). Restaurant Food Waste Action Guide. ReFED. Retrieved from https://www.refed.com/downloads/Restaurant_Guide_Web.pdf

Rosa, F. (2018). The Story of Recircle. Zero Waste Consumption \& Production. Zero Waste Europe. Retrieved from https://zerowasteeurope.eu/downloads/case-study-1-the-story-of-recircle/

Ruiz, C. X. (2018). El estado del medioambiente en Europa, in Sánchez, A. y Álvarez, C.: Informe sobre Sostenibilidad en España 2018. Cómo anticiparse a la crisis del cambio climático, Fundación Alternativas, Madrid.

Schanes, K., Dobernig, K., \& Gözet, B. (2018). Food waste matters - A systematic review of household food waste practices and their policy implications. Journal of Cleaner Production, 182, 978-991. https://doi.org/10.1016/j.jclepro.2018.02.030

Schimidt, K., \& Matthies, E. (2016). Where to start fighting the food waste problem? Identifying most promising entry points for intervention programs to reduce household food waste and overconsumption of food. Resources, Conservation \& Recycling, 139, 1-14. https://doi.org/10.1016/j.resconrec.2018.07.023

Setti, M., Banchelli, F., Falasconi, L., Segré, A., \& Vittuari, M. (2018). Consumer's food cycle and household waste. When behaviours matter. Journal of Cleaner Production, 185, 694-706. https://doi.org/10.1016/j.jclepro.2018.03.024

Stancu, V., Haugaard, P., \& Lähteenmäki, L. (2016). Determinants of consumer food waste behaviour: Two 
routes to food. Appetite, 96, 7-17. https://doi.org/10.1016/j.appet.2015.08.025

Starbucks. (2018). Reciclaje y reducción de residuos. Retrieved from http://www.starbucks.es/responsibility/environment/recycling

Stenmark, Å., Jensen, C. et al. (2016). Estimates of European food waste levels. Stockholm, FUSIONS.

Unilever Food Solutions. (2016). Abra los ojos ante los desperdicios. Trabaje de manera inteligente. Retrieved from: https://cehe.es/documents/guias/abra-los-ojos-ante-los-desperdicios.pdf

United Nations. (2015). Sustainable Development Goals. Retrieved from https://www.un.org/sustainabledevelopment/sustainable-development-goals/

Waarts, Y., Eppink, M., Oosterkamp, E., Hiller, S., Van Der Sluis, A., \& Timmermans, A. (2011). Reducing food waste: obstacles and experiences in legislation and regulations. Rapport LEI 2011-059. 128.

WRAP. (2018). The business case for reducing food loss and waste: catering. A report on behalf of champions 12.3. Retrieved from https://ec.europa.eu/food/sites/food/files/safety/docs/fw_lib_srp_wri-catering.pdf

Yeo, J., Oh, J., Cheung, H., Lee, P., \& An, A. (2019). Smart Food Waste Recycling Bin (S-FRB) to tur food waste into green energy resources. Journal of Environmental Management, 234, 290-296. https://doi.org/10.1016/j.jenvman.2018.12.088

\section{Copyrights}

Copyright for this article is retained by the author(s), with first publication rights granted to the journal.

This is an open-access article distributed under the terms and conditions of the Creative Commons Attribution license (http://creativecommons.org/licenses/by/4.0/). 